\title{
APLIKASI ANDROID HALO BALITA DENGAN METODE MADLC
}

\author{
Suryo Atmojo ${ }^{1)}$, Suzana Dewi'), Nurwahyudi Widhiyanta ${ }^{3)}$,Ruli Utami ${ }^{4)}$ \\ ${ }^{123}$ Teknik Informatika, Universitas Wijaya Putra \\ ${ }^{4}$ Sistem Informasi, Institut Teknologi Adhi Tama Surabaya \\ ${ }^{123} \mathrm{Jl}$. Raya Benowo 1-3 Surabaya \\ ${ }^{4} \mathrm{Jl}$. Arief Rahman Hakim no. 100 Surabaya \\ Email: ${ }^{1}$ suryoatmojo@uwp.ac.id, ${ }^{2}$ suzanadewi@uwp.ac.id, ${ }^{3}$ nurwahyudiwidhiyanta@uwp.ac.id, \\ ruli.utami03@gmail.com
}

\begin{abstract}
Neonatology is increasingly becoming important at this time.Many varieties of diseases and disorders are also increasing, so that it requires more attention from all people. This application is designed to better understand the science of child development. Today's technological developments are getting faster. As many (43\%) people in Indonesia own a smartphone. $83.99 \%$ of the android mobile market share is dominated by the Android operating system. The use of Android-based mobile phones in Indonesia on a large scale has encouraged many researchers to develop mobile-based learning media (m-learning). Articles and reading material such as children's health books make it difficult for readers because users have to manually look up the meaning of the term health. Based on these problems, an Android-based mobile application is needed that can be used to help parents take notes, get information and monitor growth and development, nutritional status, and immunization schedules. with this application, it makes it easier for people to access children's health information easily. The MADLC method is used in this research where the process consists of the identification phase, the design phase, the development phase, the prototyping phase, the testing phase, the deployment phase and the maintenance phase. The conclusion of this study is that the existence of an android application can help parents to be able to get information about the health and development of children.
\end{abstract}

Keyword: android, Health, MADLC, applications, children

\begin{abstract}
Abstrak
Neonatologi semakin menjadi penting pada saat ini. Banyak variasi penyakit dan kelainan pada anak yang juga semakin banyak, sehingga memerlukan perhatian yang lebih dari semua masyarakat khususnya orang tua. Aplikasi ini dirancang memenuhi agar lebih memahami ilmu tumbuh kembang anak. Perkembangan teknologi saat ini semakin cepat. Sebanyak (43\%) masyarakat di Indonesia memiliki smartphone. Pangsa pasar ponsel di indonesia sebesar 83,99\% didominasi oleh sistem operasi Android. Penggunaan telepon genggam berbasis Android di indonesia dalam skala besar, mendorong banyak peneliti untuk mengembangkan media belajar berbasis mobile (m-learning). Bahan bacaan serta artikel seperti buku kesehatan anak tidak terlalu berdampak terhadap edukasi Kesehatan anak khususnya pada orang tua, buku dirasa justru menyulitkan pembaca karena pengguna harus mencari arti secara manual pada setiap istilah kesehatan. Berdasarkan permasalah tersebut, dibutuhkan aplikasi mobile untuk berbasis android yang dapat digunakan untuk membantu para orang tua untuk mencatat, mendapatkan informasi dan memonitoring tumbuh kembang, status gizi, dan jadwal imunisasi. dengan adanya aplikasi ini, memudahkan masyarakat untuk akses informasi kesehatan anak dengan mudah. Pada penelitian menggunakan metode MADLC sebagai metode pengembangan aplikasi dimana prosesnya terdiri dari tahapan identifikasi, tahapan desain, tahapan development, tahapan prototyping, tahapan testing, tahapan deployment serta tahapan maintenance. Kesimpulan dari penelitian ini adalah dengan adanya aplikasi android dapat membantu orang tua untuk dapat mendapatkan informasi seputar kesehatan dan neonatologi.
\end{abstract}

Kata Kunci: android, Kesehatan, madlc, aplikasi, anak

\section{PENDAHULUAN}

Android adalah sebuah sistem operasi untuk perangkat mobile berbasis Linux yang mencakup sistem operasi, middleware dan aplikasi. Android menyediakan platform terbuka bagi para pengembang untuk menciptakan aplikasi mereka. (Nazarudin safaat-android pemrograman aplikasi mobile smarthphone dan tablet pc berbasis android). Android memiliki market share $87 \%$ di dunia dan diperkirakan akan tetap bertahan pada masa yang akan datang. popularitas Android yang terus berkembang pesat inilah yang jadi alasan utama bahwa mengembangkan 
aplikasi berbasis Android adalah langkah yang sangat baik.

Salah satu tugas utama dari Kementerian Kesehatan yaitu meningkatkan status kesehatan anak khususnya pada bayi dan balita. Masih tingginya angka sakit serta angka kematian yang terjadi pada usia tersebut memerlukan perhatian serta dukungan dari semua lapisan masyarakat. Kendala dari usaha tersebut adalah masih rendahnya pengetahuan masyarakat pada kesehatan, deteksi dini penyakit pada anak serta bagaimana merawat anak di rumah.

Anak merupakan harapan bagi setiap keluarga. Selain itu Setiap keluarga juga mengharapkan anaknya pada kemudian hari bertumbuh kembang secara optimal (sehat fisik mental atau kognitif dan sosial), dapat dibanggakan, dan bermanfaat bagi nusa dan bangsa. Seorang anak harus mendapat perhatian sejak mereka masih di dalam kandungan sampai mereka menjadi manusia dewasa karena anak merupakan aset bangsa. Tumbuh Kembang adalah proses berkelanjutan yang terjadi dari tahap konsepsi berlangsung sampai fase dewasa. Seiring tahap proses mencapai dewasa, anak harus melalui berbagai tahapan fase tumbuh kembang [1]. Tercapainya tumbuh kembang secara optimal tergantung pada potensi pada seorang anak. Tingkat tercapainya potensi biologi pada anak didapatkan pada hasil lingkungan biofisik psikososial serta interaksi antara faktor genetik. Proses yang unik dan hasil akhir yang berbeda-beda memberikan ciri tersendiri pada setiap anak. Pengetahuan secara rinci tentang dasar tumbuh kembang anak sangat penting dan harus dikuasai oleh para orangtua [2]. Bila dasar ilmu ini kuat, orang tua akan sangat mudah mengetahui setiap kali ada penyimpangan dan segera dapat memberikan tindakan (tumbuh kembang anak edisi 2). Untuk mencapai tumbuh kembang optimal seorang anak diperlukan persiapan sejak usia dini bahkan sebelum pernikahan. faktor-faktor yang dapat mempengaruhi buruknya tumbuh kembang anak harus dihindari, sebaliknya faktor-faktor yang mempengaruhi baiknya tumbuh kembang tentunya harus selalu diusahakan [3]. saat ini organisasi profesi dokter anak Indonesia sangat memperhatikan kemajuan ilmu tumbuh kembang anak, demikian juga pemerintah sudah membuat program skrining sampai intervensi yang sudah terintegrasi mulai dari tingkat pelayanan kesehatan di Posyandu sampai tingkat pelayanan rujukan di rumah sakit. Dengan dibuatnya aplikasi mengenai tumbuh kembang anak ini merupakan langkah yang tepat dalam menyediakan sumber informasi yang tepat bagi bagi orang tua anak. harus diakui bahwa perkembangan ilmu kedokteran berlangsung dengan cepat, sementara itu referensi buku keilmuan tumbuh kembang masih terbatas. aplikasi ini diharapkan dapat digunakan secara optimal sehingga pada akhirnya diharapkan akan meningkatkan kualitas hidup anak untuk menyongsong Indonesia yang lebih sejahtera.

Metode yang diterapkan pada penelitian ini adalah mobile application development lifecycle (MADLC). Metode ini dipilih karena memungkinkan pendekatan secara sistematis pada pengembangan aplikasi mobile dimana pada prosesnya berbeda dengan aplikasi desktop.
Ada tujuh fase dalam MADLC yaitu identifikasi, pengembangan desain, pembuatan prototipe, pengujian, penyebaran dan pemeliharaan. Kebanyakan aplikasi berorientasi industri dikembangkan menggunakan MADLC [4]. Model ini sangat cocok untuk digunakan karena lebih akurat, sistematis dan memiliki fase yang mudah dimengerti pengembangan aplikasi.[5]. Aplikasi ini diharapkan hadir untuk menjawab problematika kesehatan di lingkungan masyarakat. pembuatan aplikasi ini didasari oleh tiga permasalahan keseharian berikut ini yaitu banyak orang yang tidak tahu bahwa di tiap tahapan perkembangan hidup manusia mulai dari bayi menjadi balita remaja lalu dewasa sampai menjadi lansia membutuhkan perhatian khusus khususnya gizi dalam perkembangannya, banyak orang tua tidak tahu bagaimana memperhatikan proses tumbuh kembang anaknya, susahnya mencari informasi referensi tentang tumbuh kembang anak yang update, banyak orang yang lupa mencatat perkembangan gizinya ataupun keluarganya [6]. Dari empat permasalahan tadi, lahirlah ide untuk membuat aplikasi Hello balita, gimana merupakan aplikasi referensi tumbuh kembang anak yang informatif berbasis aplikasi Android

\section{METODE PENELITIAN}

Metode penelitian yang digunakan pada tahap pengembangan aplikasi mobile ini adalah MADLC atau mobile application development lifecycle model [7]. Pada metode MADLC terdiri dari 7 tahapan pengembangan yaitu:

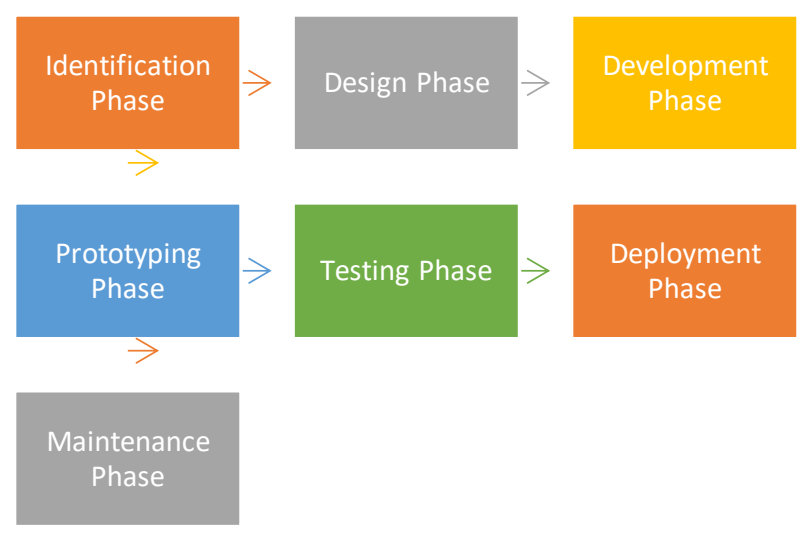

Gambar 1. Tahapan Metode MADLC
1. Identification Phase
2. Design Phase
3. Development Phase
4. Prototyping Phase
5. Testing Phase
6. Deployment Phase
7. Maintenance Phase

Pertama adalah tahapan identification phase merupakan tahapan Analisa. Pada tahap ini dilakukan Analisa pengguna sistem guna mengetahui siapa saja actor yang terlibat dalam mejalankan sistem. Pada tahap ini juga 
dilakukan Analisa data yang diperlukan agar sistem aplikasi dapat memberikan informasi yang bermanfaat bagi pengguna. Kedua adalah tahapan Design Phase dimana pada tahapan ini dilakukan perancangan desain storyboard. Ketiga adalah tahapan Development Phase dimana pada tahapan ini akan dilakukan pembuatan program. Keempat yaitu prototyping Phase dimana pada tahapan ini akan dilakukan pengecekan fungsi pada setiap baris program. Kelima yaitu Testing Phase dimana pada tahapan ini akan dilakukan pengujian program secara keseluruhan pada emulator Android [8]. Pada proses yang ke enam yaitu Deployment Phase dimana pada tahapan ini, aplikasi akan dipublikasikan. Proses yang terakhir adalah Maintenance Phase dimana pada tahap ini akan dilakukan pemeliharaan aplikasi secara berkesinambungan.

\section{HASIL DAN PEMBAHASAN}

\section{Use Case Diagram}

Use case menggambarkan kebutuhan fungsional sistem, kemudian dibuat scenario dimana menggambarkan urutan dari skenario. Aplikasi ini terdiri dari 10 use case dengan aktor user dan admin. Use case diagram aplikasi dapat dilihat pada gambar dibawah ini.

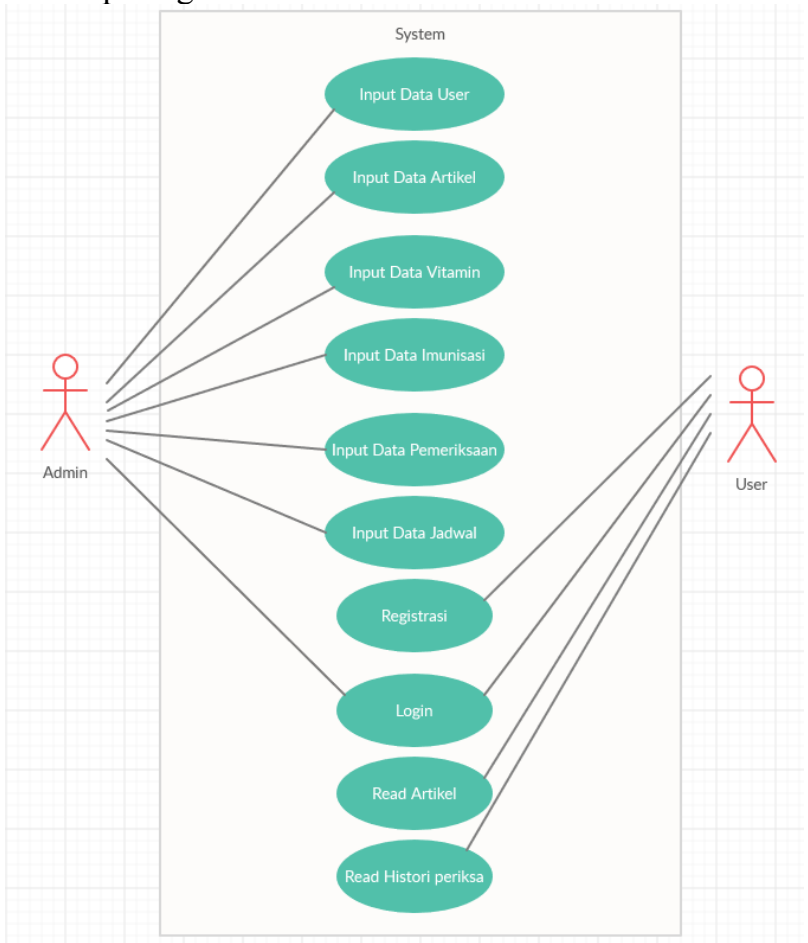

Gambar 2. Use Case Aplikasi Diary Kesehatan

Definisi dari aktor dapat dilihat pada table dibawah ini

No Aktor

Keterangan

1 Admin

Aktor ini mengelola data secara keseluruhan

2 User
No Nama Use Keterangan

1 mengelola data

user

2 mengelola data artikel

3 mengelola data

vitamin

$4 \quad$ Mengelola data imunisasi

$5 \quad$ Mengelola

data pemeriksaan

6 Mengelola data jadwal

Berfungsi create, read, update, delete data user

Berfungsi create, read, update, delete data artikel

Berfungsi create, read, update, delete data vitamin

Berfungsi create, read, update, delete data imunisasi

Berfungsi create, read, update, delete data pemeriksaan

Berfungsi create, read, update, delete data jadwal

\section{Halaman Login :}

Pada antarmuka ini berfungsi untuk memvalidasi pengguna sesuai dengan data registrasi. Berikut adalah antarmuka login

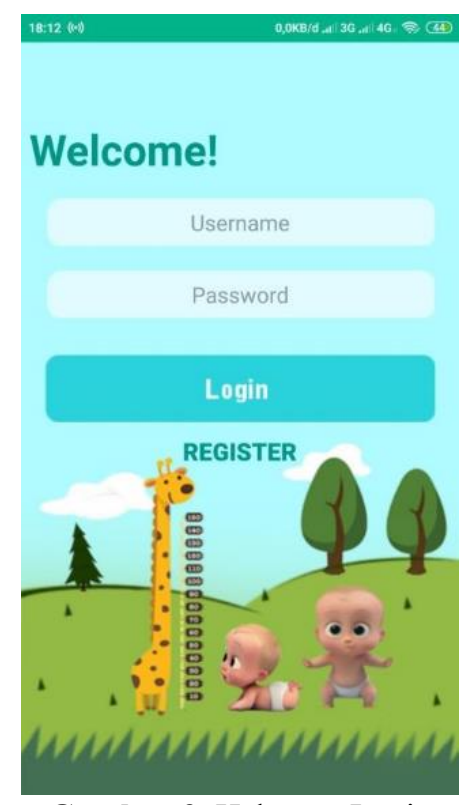

Gambar 3. Halaman Login

\section{Halaman Registrasi}

Registrasi merupakan tampilan yang berisi form input untuk melakukan registrasi pengguna baru. Form terdiri no kk, nama ayah, nama ibu, nama balita, tanggal lahir balita, jenis kelamin, alamat, nomor telepon, username, password. 


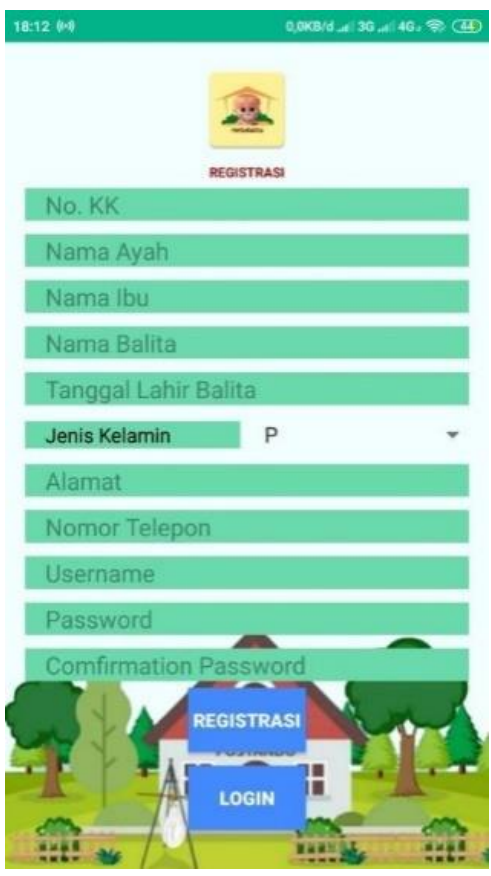

Gambar 3. Halaman Login

Antar muka ini berfungsi untuk mengkonfromasi registrasi user baru.

\section{Halaman Menu}

Pada Expand Left terdapat beberapa menu yang disediakan. Dapat memilih menu yang diinginkan seperti home, pemeriksaan, artikel kesehatan, kontak kader, dan about us, setelah itu akan menampilkan halaman menu yang dituju

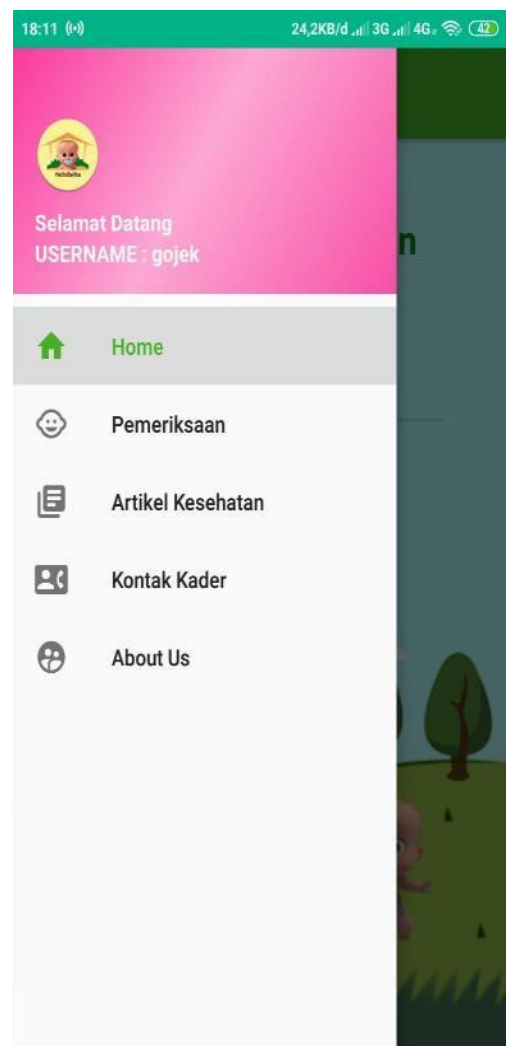

Gambar 4. Halaman Menu

\section{Halaman Artikel Kesehatan}

Pada halaman artikel kesehatan merupakan menu informasi yang dimana merupakan menu yang digunakan untuk mengetahui informasi mengenai kesehatan tumbuh kembang balita.

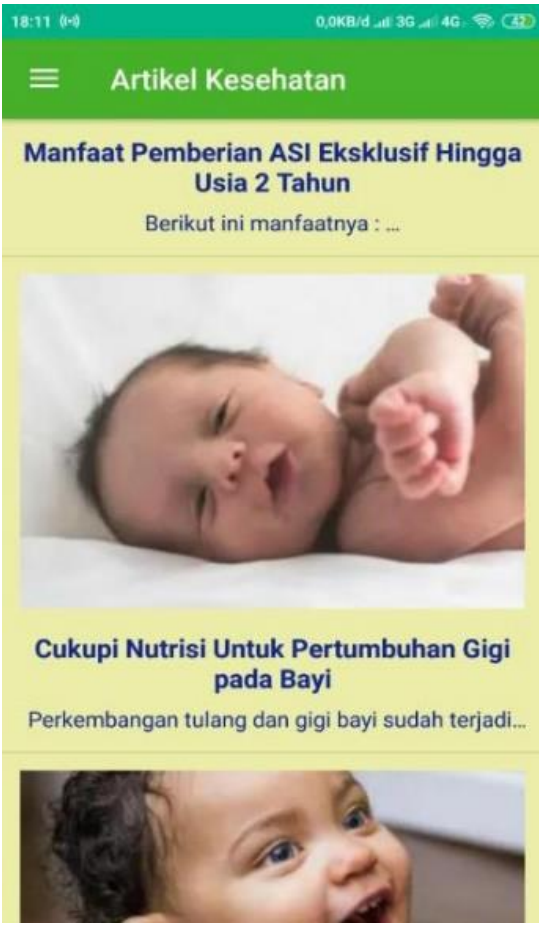

Gambar 5. Halaman Artikel

\section{Pengujian Aplikasi}

\begin{tabular}{|l|l|l|l|}
\hline $\begin{array}{l}\text { Aktifitas } \\
\text { Pengujian }\end{array}$ & $\begin{array}{l}\text { Realisasi } \\
\text { yang } \\
\text { diharapkan }\end{array}$ & Hasil & \multicolumn{2}{l|}{ Status } \\
\hline $\begin{array}{l}\text { input data } \\
\text { user }\end{array}$ & $\begin{array}{l}\text { add user } \\
\text { baru pada } \\
\text { halaman } \\
\text { registrasi }\end{array}$ & $\begin{array}{l}\text { Data user } \\
\text { baru dapat } \\
\text { ditambahkan }\end{array}$ & \multicolumn{2}{|l}{} \\
\hline $\begin{array}{l}\text { input data } \\
\text { artikel pada } \\
\text { menu admin }\end{array}$ & $\begin{array}{l}\text { add artikel } \\
\text { baru pada } \\
\text { menu admin }\end{array}$ & $\begin{array}{l}\text { Data artikel } \\
\text { baru dapat } \\
\text { ditambahkan }\end{array}$ & $\sqrt{ }$ \\
\hline $\begin{array}{l}\text { Imput data } \\
\text { pemeriksaan }\end{array}$ & $\begin{array}{l}\text { add data } \\
\text { pemeriksaan } \\
\text { baru }\end{array}$ & $\begin{array}{l}\text { Data } \\
\text { pemeriksaan } \\
\text { baru dapat } \\
\text { ditambahkan }\end{array}$ & V \\
\hline Login & $\begin{array}{l}\text { Proses login } \\
\text { dapat } \\
\text { dilakukan } \\
\text { dengan } \\
\text { menginputk } \\
\text { an username } \\
\text { dan } \\
\text { password }\end{array}$ & $\begin{array}{l}\text { User dan } \\
\text { admin dapat } \\
\text { melakukan } \\
\text { proses Login }\end{array}$ & $\sqrt{ }$ \\
\hline $\begin{array}{l}\text { User dapat } \\
\text { melihat } \\
\text { artikel } \\
\text { terbaru }\end{array}$ & $\begin{array}{l}\text { Aplikasi } \\
\text { android } \\
\text { dapat } \\
\text { menampilka } \\
\text { n artikel }\end{array}$ & $\begin{array}{l}\text { User dapat } \\
\text { melihat } \\
\text { semua artikel } \\
\text { diinputkan }\end{array}$ & $\sqrt{ }$ \\
\hline
\end{tabular}




\begin{tabular}{|l|l|l|l|}
\hline & $\begin{array}{l}\text { yang } \\
\text { diinputkan }\end{array}$ & \\
\hline User dapat & Aplikasi & User dapat & $\sqrt{ }$ \\
melihat & android & melihat & \\
Riwayat & dapat & semua & \\
pemeriksaan & menampilka & Riwayat & \\
& n Riwayat & periksa yang & \\
& pemeriksaan & telah & \\
& yang & diinputkan & \\
& diinputkan & & \\
\hline
\end{tabular}

\section{KESIMPULAN}

Berdasarkan uraian serta analisa dan proses desain perencanaan yang telah dilakukan, dapat disimpulkan aplikasi android diary kesehatan dan tumbuh kembang pada anak dapat mempermudah orang tua untuk mendapatkan informasi tentang kesehatan dan tumbuh kembang anak. Keunggulan dari aplikasi ini yaitu : Cepat dan mudah dibaca, Mencantumkan materi terbaru. Menyediakan informasi pengobatan/dosis penting

Sistem ini masih banyak kekurangan dan kelemahanannya, sehingga peneliti menerima kritik dan saran yang membangun dalam pengembangan dan perbaikan sistem ini selanjutnya

\section{Saran}

1. Perlu pengembangan pada aplikasi menjadi multi platform tidak terbatas pada sistem android sehingga dapat memberikan manfaat bagi user dan masyarakat.

2. Keamanan sistem dan keamanan data user harus lebih ditingkatkan karena sistem ini menyimpan seluruh data Kesehatan user

3. Aplikasi ini dapat berkembang ke arah yang lebih professional (didukung oleh layanan konsultasi dokter) untuk dapat menyediakan informasi yang baik khususnya riwayat periksa anak

\section{Daftar Pustaka}

[1] S. Soedjatmiko, "Deteksi Dini Gangguan Tumbuh Kembang Balita," Sari Pediatr., vol. 3, no. 3, pp. 175-188, 2016.

[2] D. I. P. Gunadi, "Peran Orang Tua Dalam Optimalisasi Tumbuh Kembang Anak Untuk Membangun Karakter Jujur,” Ina. June, vol. 25, 2019.

[3] S. Nahriyah, "Tumbuh kembang anak di era digital," Risalah, vol. 4, no. 1, pp. 65-74, 2017.

[4] M. Y. Darus, M. S. A. Hazani, and N. Awang, "Mobile Self-Management System for University Students using Mobile Application Development Lifecycle (MADLC)," J. Telecommun. Electron. Comput. Eng., 2017.

[5] L. Shanmugam, S. F. Yassin, and F. Khalid, "Incorporating the elements of computational thinking into the Mobile Application
Development Life Cycle (MADLC) model," Int. J. Eng. Adv. Technol., 2019.

[6] M. N. Hairunis, H. Salimo, and Y. L. R. Dewi, "Hubungan status gizi dan stimulasi tumbuh kembang dengan perkembangan balita," Sari Pediatr., vol. 20, no. 3, pp. 146-151, 2018.

[7] A. Kaur and K. Kaur, "Systematic literature review of mobile application development and testing effort estimation," J. King Saud Univ. Inf. Sci., 2018.

[8] Y. G. Shawai and M. A. Almaiah, "Malay language mobile learning system (MLMLS) using NFC technology," Int. J. Educ. Manag. Eng., vol. 8, no. 2, p. 1, 2018. 